\title{
Glucagon-like peptide 1 analogue therapy directly modulates innate immune-mediated inflammation in individuals with type 2 diabetes mellitus
}

\author{
Andrew E. Hogan • Gadintshware Gaoatswe • \\ Lydia Lynch • Michelle A. Corrigan • Conor Woods • \\ Jean O'Connell • Donal O'Shea
}

Received: 21 August 2013 / Accepted: 27 November 2013 / Published online: 21 December 2013

(C) Springer-Verlag Berlin Heidelberg 2013

\begin{abstract}
Aims/hypothesis Glucagon-like peptide 1 (GLP-1) is a gut hormone used in the treatment of type 2 diabetes mellitus. There is emerging evidence that GLP-1 has anti-inflammatory activity in humans, with murine studies suggesting an effect on macrophage polarisation. We hypothesised that GLP-1 analogue therapy in individuals with type 2 diabetes mellitus would affect the inflammatory macrophage molecule soluble CD163 (sCD163) and adipocytokine profile.

Methods We studied ten obese type 2 diabetes mellitus patients starting GLP-1 analogue therapy at a hospital-based diabetes service. We investigated levels of sCD163, TNF- $\alpha$,
\end{abstract}

A. E. Hogan · G. Gaoatswe • M. A. Corrigan • C. Woods •

J. O'Connell • D. O'Shea

Obesity Immunology, Education and Research Centre, St Vincent's

University Hospital, University College Dublin, Dublin, Ireland

A. E. Hogan

National Children's Research Centre, Our Lady's Children's

Hospital, Dublin, Ireland

L. Lynch

Haematology and Oncology, BIMDC, Harvard Medical School,

Boston, MA, USA

D. O'Shea

Department of Endocrinology, St Columcille's Hospital, Health

Service Executive, Loughlinstown, Ireland

D. O'Shea $(\bowtie)$

Department of Endocrinology, St Vincent's University Hospital, Elm Park, Dublin 4, Ireland

e-mail: info@dosheaendo.ie

Present address:

L. Lynch

Rheumatology, Allergy and Immunology,

Brigham and Women's Hospital, Boston, MA, USA
IL-1 $\beta$, IL-6, adiponectin and leptin by ELISA, before and after 8 weeks of GLP-1 analogue therapy.

Results GLP-1 analogue therapy reduced levels of the inflammatory macrophage activation molecule sCD163 (220 ng/ml vs $171 \mathrm{ng} / \mathrm{ml}, p<0.001)$. This occurred independent of changes in body weight, fructosamine and $\mathrm{HbA}_{1 \mathrm{c}}$. GLP-1 analogue therapy was associated with a decrease in levels of the inflammatory cytokines TNF- $\alpha$ (264 vs $149 \mathrm{pg} / \mathrm{ml}, p<0.05$ ), IL-1 $\beta$ $(2,919$ vs $748 \mathrm{pg} / \mathrm{ml}, p<0.05)$ and IL-6 (1,379 vs $461 \mathrm{pg} / \mathrm{ml}$ $p<0.05)$ and an increase in levels of the anti-inflammatory adipokine adiponectin (4,480 vs 6,290 pg/ml, $p<0.002)$. Conclusions/interpretation In individuals with type 2 diabetes mellitus, GLP-1 analogue therapy reduces the frequency of inflammatory macrophages. This effect is not dependent on the glycaemic or body weight effects of GLP-1.

Keywords GLP-1 · Inflammation · Macrophage · Obesity

$\begin{array}{ll}\text { Abbreviations used } \\ \text { GLP-1 } & \text { Glucagon-like peptide } 1 \\ \text { iNKT } & \text { Invariant natural killer T } \\ \text { PBMC } & \text { Peripheral blood mononuclear cell } \\ \text { sCD163 } & \text { Soluble CD163 }\end{array}$

\section{Introduction}

Chronic inflammation is a major contributor to the insulin resistance that underpins obesity and type 2 diabetes. Macrophages play a distinct role in obesity-induced insulinresistance, driving adipose tissue inflammation [1]. In healthy individuals, macrophages are regulatory M2 cells producing the anti-inflammatory cytokine IL-10. In obesity, macrophages are polarised to the M1 inflammatory phenotype, producing the proinflammatory cytokine IL-1 $\beta$ [2]. As 
macrophages become proinflammatory, removal of the haptoglobin-haemoglobin receptor CD163 becomes upregulated and is measurable as soluble CD163 (sCD163). sCD163 is strongly associated with insulin resistance independently of inflammatory markers such as TNF- $\alpha$ [3]. The gastrointestinal tract, its microbiome and gut hormones are increasingly recognised as playing a key role in the crosstalk between adipose tissue, immune cells and metabolic processes [4]. Glucagon-like peptide 1 (GLP-1) is a gastrointestinal peptide hormone postprandially released by intestinal L cells. GLP-1 analogues and GLP-1 receptor agonists, are now used in the management of type 2 diabetes. There is a growing body of literature describing the extra-pancreatic effects of GLP-1, including an emerging role in inflammation and regulation of macrophages [5-8]. We previously observed changes in invariant natural killer T (iNKT) cell number and function in obese diabetic patients following GLP-1 analogue therapy [9]. The iNKT cell is a key regulator of macrophage function and adipose tissue biology [10]. We therefore investigated the effect of GLP-1 analogue therapy on macrophage-driven inflammation and circulating adipocytokines, in a cohort of ten subjects with type 2 diabetes.

\section{Methods}

Ethics statement and participants St Vincent's University Hospital Medical Research and Ethics Committee approved this study. Written informed consent was obtained from every participant prior to the start of any research activities. We enrolled ten participants with type 2 diabetes who were due to commence GLP-1 analogue therapy for clinical indications (Table 1). All patients were on stable doses of oral hypoglycaemic medications and their weight had been stable for 4 weeks before the study. The dosages of statins and other drugs were not changed during the study. Each

Table 1 Clinical characteristics of the participants with type 2 diabetes mellitus commencing GLP-1 analogue $(n=10)$

\begin{tabular}{llll}
\hline & Baseline & Post-GLP-1 & $p$ value \\
\hline Gender & 3 women, 7 men & - & - \\
Age (years) & $54.6 \pm 8.4$ & - & - \\
Diabetes duration (years) & $7.7 \pm 5.4$ & - & - \\
Weight $(\mathrm{kg})$ & $128(83-166)$ & $125(80-165)$ & 0.9 \\
$\mathrm{HbA}_{1 \mathrm{c}}$ & & & \\
$\quad \mathrm{mmol}_{\mathrm{mmol}}$ & $72(45-104)$ & $63(42-86)$ & 0.33 \\
$\quad \%$ & $8.7(6.3-11.7)$ & $7.9(6.0-9.7)$ & 0.05 \\
Fructosamine $(\mu \mathrm{mol} / \mathrm{l})$ & $299(432-211)$ & $266(347-210)$ & 0.07 \\
sCD163 $(\mathrm{ng} / \mathrm{ml})$ & $226(187-260)$ & $176(115-229)$ & 0.0006 \\
\hline
\end{tabular}

Data are expressed as mean $\pm \mathrm{SD}$ or median values with range in parentheses participant self-administered liraglutide by subcutaneous injection at a dosage of $0.6 \mathrm{mg}$ once daily for 2 weeks and then $1.2 \mathrm{mg}$ once daily thereafter. Before and after 8 weeks of therapy, the research participants attended for a visit in the early morning after an overnight fast. We recorded reported adherence to treatment and weight and obtained a venous blood sample. The sampled blood was used to determine metabolic status and to assess peripheral blood mononuclear cell (PBMC) function and serum analytes. A cohort of age- and sex-matched lean, non-diabetic controls were also recruited as comparators and experimental controls.

Human blood preparations Human PBMCs were prepared by density gradient centrifugation over LymphoPrep (Nycomed, Oslo, Norway) at $400 \mathrm{~g}$ for $25 \mathrm{~min}$. Cells were then washed twice with HBSS supplemented with HEPES buffer solution (Invitrogen Life Technologies, Dublin, Ireland) and antibiotics. Cell pellets were re-suspended in $1 \mathrm{ml}$ of RPMI 1640 medium and cell yields and viability were assessed by ethidium bromide-acridine orange staining.

Analysis of cytokine and sCD163 Patient PBMCs were stimulated with phorbol myristate acetate (PMA) $(10 \mathrm{ng} / \mathrm{ml})$ and ionomycin $(1 \mu \mathrm{g} / \mathrm{ml})$, or lipopolysaccharide (LPS) $(10 \mathrm{ng} / \mathrm{ml})$ or media alone. After $24 \mathrm{~h}$, supernatant concentrations of IL- $1 \beta$, TNF- $\alpha$ and IL- 6 were determined by ELISA (Biolegend, San Diego, CA, USA). sCD163 was measured in the serum of patients using a quantikine ELISA kit (R\&D Systems, Abingdon, UK).

THP-1-derived macrophages Macrophages were derived from the monocytic THP-1 cell line by stimulating with PMA $(10 \mathrm{ng} / \mathrm{ml})$ for $24 \mathrm{~h}$. Macrophages were polarised by culturing with either IFN- $\gamma$ (M1 phenotype) or IL-4 (M2 phenotype) during differentiation. The cells were then stimulated with LPS in the absence or presence of GLP-1 analogue for $24 \mathrm{~h}$, and the cells' supernatants assessed for cytokine secretion by ELISA.

Statistical analysis All statistical analyses were performed with Prism version 6.0 software (Graphpad, San Diego, CA, USA). Data are presented as mean \pm SEM or median with range in parentheses. The groups were compared using Student's $t$ test or Mann-Whitney $U$ test, as appropriate. Correlation analysis was performed using Spearman's rank correlation test. A $p$ value $<0.05$ was considered statistically significant.

\section{Results}

The clinical characteristics of the ten type 2 diabetes patients are presented in Table $1 . \mathrm{HbA}_{1 \mathrm{c}}$, weight and fructosamine did improve in some patients after 8 weeks of GLP-1 analogue 
therapy, although the median change for the group was not statistically significant (Table 1).

GLP-1 analogue therapy decreases proinflammatory macrophages and reduces inflammation in type 2 diabetes Type 2 diabetic patients have significantly higher levels of the inflammatory macrophage associated-molecule sCD163 compared with a cohort of age and sex matched non-obese controls (Fig. 1a). There was a significant decrease in the levels of sCD163 post GLP-1 treatment $(220 \mathrm{ng} / \mathrm{ml}$ vs $171 \mathrm{ng} / \mathrm{ml}$, $p<0.001$ ), indicating a reduction in the number of inflammatory macrophages (Fig. 1b). The change in sCD163 levels showed no correlation with change in $\mathrm{HbA}_{1 \mathrm{c}}(r=-0.09$, $p=0.8)$, change in weight $(r=-0.26, p=0.46)$ or change in fructosamine $(r=-0.05, p=0.9)$ (Fig. 1c-e). One of the largest reductions in sCD163 levels $(-83 \mathrm{ng} / \mathrm{ml})$ occurred in a patient who had no clinically significant change in weight $(-1.2 \mathrm{~kg})$ or $\mathrm{HbA}_{1 \mathrm{c}}$ level, $+2 \mathrm{mmol} / \mathrm{mol}(+0.2 \%)$. Conversely, the smallest reduction in sCD163 levels $(-19 \mathrm{ng} / \mathrm{ml})$ occurred in a patient with a decrease in $\mathrm{HbA}_{1 \mathrm{c}}$ of $20 \mathrm{mmol} / \mathrm{mol}(-1.9 \%)$.

GLP-1 analogue therapy was associated with a reduction in PBMC production of the proinflammatory cytokines TNF- $\alpha$

(264 vs $149 \mathrm{pg} / \mathrm{ml}, p<0.05)$, IL-1 $\beta$ (2,919 vs $748 \mathrm{pg} / \mathrm{ml}$, $p<0.05)$ and IL-6 (1,379 vs $461 \mathrm{pg} / \mathrm{ml} p<0.05)$ (Fig. $1 \mathrm{f}-\mathrm{h})$. GLP-1 analogue therapy resulted in an increase in serum adiponectin $(4,480$ vs $6,290 \mathrm{pg} / \mathrm{ml}, p<0.002)$ and a trend towards a decrease in serum leptin $(5,250$ vs $4,054 \mathrm{pg} / \mathrm{ml}$ $p=0.1)$, consistent with a reduction in adipose inflammation (Fig. 1i, j).

GLP-1 analogue therapy modulated macrophage function in vitro, resulting in decreased IL- $1 \beta$ production $(380 \mathrm{pg} / \mathrm{ml}$ vs $267 \mathrm{pg} / \mathrm{ml}, p<0.001)$ by M1 macrophages and increased IL-10 (15 pg/ml vs $33 \mathrm{pg} / \mathrm{ml}, p<0.001)$ production by M2 macrophages (Fig. 1k, l).

\section{Discussion}

This work indicates that, in individuals with type 2 diabetes mellitus, GLP-1 analogue therapy causes a reduction in the levels of the inflammatory macrophage-derived sCD163. The reduction in SCD163 showed no correlation with the change in $\mathrm{HbA}_{1 \mathrm{c}}$, fructosamine or body weight. This supports a direct effect of GLP-1 on innate immune cell function.

Fig. 1 GLP-1 analogue therapy decreases sCD163 levels in type 2 diabetes (T2DM) and alters the adipocytokine profile. (a) Serum sCD163 levels in cohort of T2DM participants $(n=10)$ compared with lean, healthy controls $(n=5)$. (b) Serum sCD163 levels in cohort of T2DM participants before and after 8 weeks GLP-1 analogue therapy $(n=10)$. Correlation plots comparing change in $(\Delta) \mathrm{SCD} 163$ vs $\Delta$ weight $(r=-0.26, p=0.46)$ (c), $\Delta \mathrm{HbA}_{1 \mathrm{c}}(r=-0.09, p=0.8)$ (d) or $\Delta$ fructosamine $(r=-0.05$, $p=0.9$ ) (e) after 8 weeks of GLP1 analogue therapy. Production of TNF- $\alpha$ (f), IL-1 $\beta$ (g) or IL-6 (h) by PBMCs isolated from T2DM participants $(n=10)$ before and after 8 weeks of GLP-1 analogue therapy. Serum leptin (i) or adiponectin (j) levels in cohort of T2DM participants before and after 8 weeks of GLP-1 analogue therapy $(n=10)$. Effect of GLP-1 analogue treatment on levels of IL-1 $\beta(\mathbf{k})$ and IL-10 (l) produced by THP-1-derived macrophages in vitro $(n=3) . * p<0.05$,

${ }^{* *} p<0.01, * * * p<0.001$
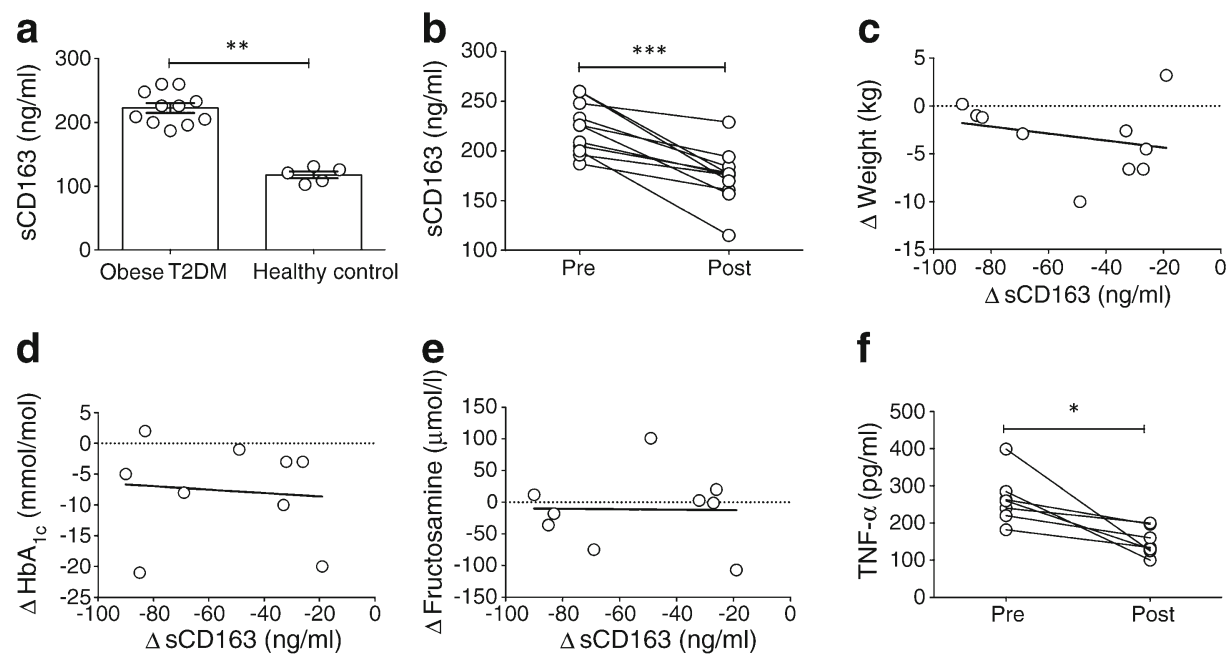

\section{f}
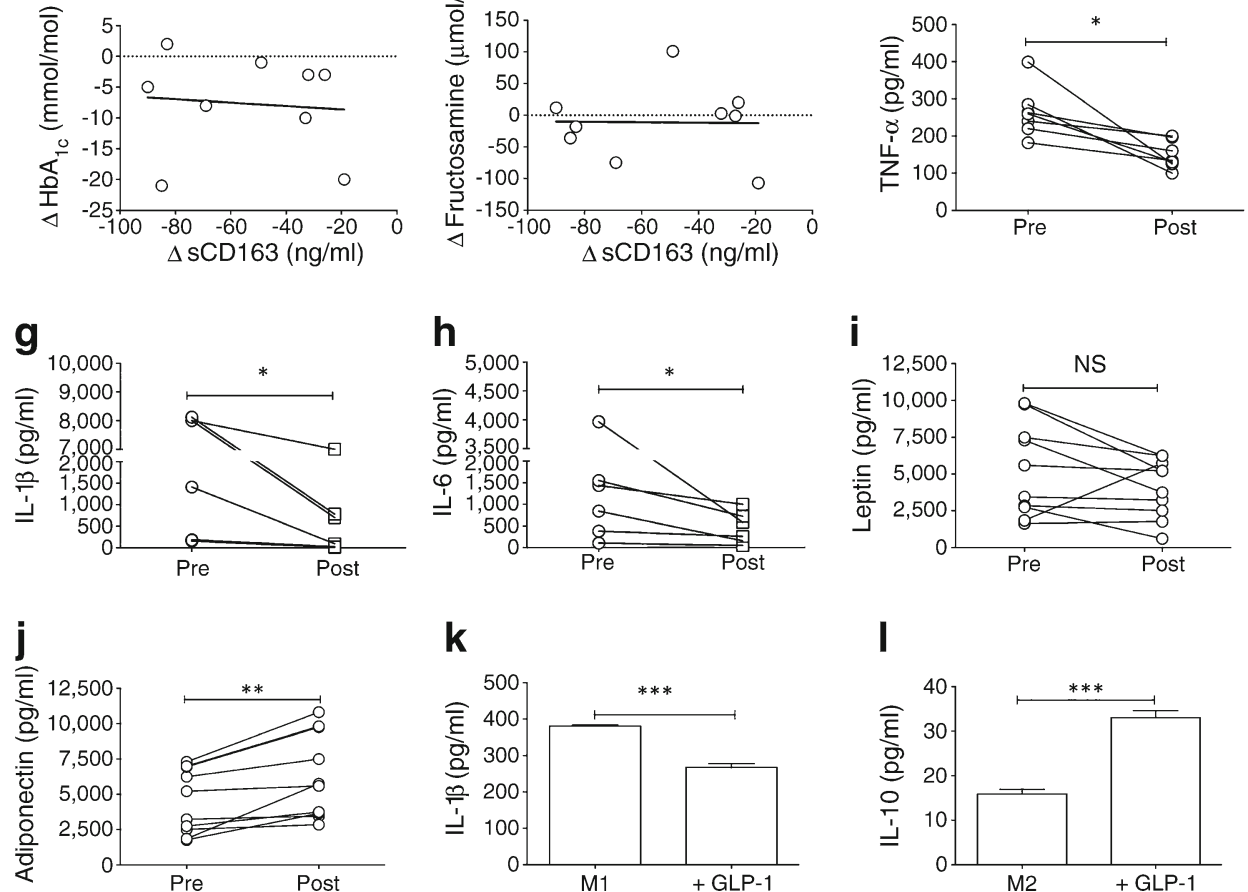

k

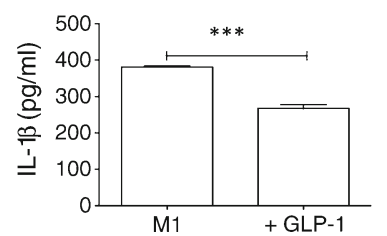

I

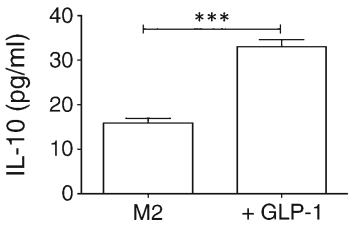


We have previously demonstrated that GLP-1 regulates invariant natural killer T (iNKT) cells, which are a rare subset of innate $\mathrm{T}$ cells involved in regulating macrophage and adipose tissue biology [10]. In humans, GLP-1 analogue therapy increases circulating iNKT cell frequency and activates anti-inflammatory pathways within the iNKT cell. Dietinduced obesity results in the loss of iNKT cells from murine peripheral blood and adipose tissue, which in turn results in the switching of macrophages from the M2 state to the proinflammatory M1 state. We therefore studied sCD163 as a marker of inflammatory macrophages to establish the effect of GLP-1 analogue therapy on macrophage polarisation in humans. Our finding that GLP-1 decreases SCD163 levels in patients is in line with a recent study of GLP-1 overexpression in obese mice that resulted in increased thermogenesis and polarisation of macrophages from the M1 to the M2 phenotype [7]. While iNKT cell instruction of macrophage activation could account for this, our in vitro data demonstrate a direct effect of GLP-1 on macrophage polarisation.

Chronic inflammation driven by altered cytokine production plays a central role in the insulin resistance that underpins obesity and type 2 diabetes. Inflammatory macrophages are a major source of proinflammatory cytokines such as TNF- $\alpha$ and IL-1 $\beta$. These cytokines lead to increased insulin resistance via a number of mechanisms, including activation of inflammatory pathways, serine phosphorylation of the insulin receptor and insulin receptor substrate 1 , and increased serum and hepatic triacylglycerol levels [11, 12]. We provide evidence for a decrease in PBMC production of the inflammatory cytokines TNF- $\alpha$, IL- $1 \beta$ and IL- 6 in patients treated with GLP-1 analogue. This may contribute to the improved insulin sensitivity observed in response to GLP-1 analogue therapy.

Our finding that adiponectin levels were significantly increased in patients treated with GLP-1 suggests an effect on adipose tissue inflammation. As discussed earlier, adipose tissue is a major contributor to obesity-driven inflammation, with infiltrating cells such as macrophages and T cells shaping the cytokine profile; however, adipocytes themselves play a role in this through the production of adipokines such as adiponectin and leptin. Adiponectin is exclusively produced by adipocytes and has anti-inflammatory and insulinsensitising properties. In healthy, lean adipose tissue, adiponectin is abundant, but in inflamed obese adipose tissue, adiponectin secretion is reduced and leptin is increased.

This study does not address whether the effect of GLP-1 on adipocyte tissue inflammation is direct, is immune cell mediated or occurs as a result of metabolic change, and highlights the lack of a control group as a weakness of this study. However, our in vitro work presented here, showing a decrease in IL- $1 \beta$ production by M1 macrophages and an increase in IL-10 production by M2 macrophages in response to GLP-1, supports a direct immune effect. This is consistent with our findings in vivo and the findings of Lee et al in murine studies [7] and indicates an effect of GLP-1 at a number of levels within the inflammatory cascade.

In summary, our findings demonstrate that GLP-1 analogue therapy has effects on innate immune cell-driven inflammation and adipose tissue function.

Funding AEH is supported by a fellowship from the National Children's Research Centre.

Duality of interest The authors declare that there is no duality of interest associated with this manuscript.

Contribution statement AEH, LL, GG, CW, MAC, JOC and DOS designed the study, analysed clinical and scientific data and wrote the manuscript. GG and $\mathrm{CW}$ recruited the patients and controls, collated the clinical data for the manuscript. AEH and MAC performed the experiments and prepared the figures for the manuscript. AEH and DOS revised the manuscript. All authors approved final manuscript.

\section{References}

1. Dalmas E, Clément K, Guerre-Millo M (2011) Defining macrophage phenotype and function in adipose tissue. Trends Immunol 32:307314

2. Fujisaka S, Usui I, Bukhari A et al (2009) Regulatory mechanisms for adipose tissue M1 and M2 macrophages in diet-induced obese mice. Diabetes 58:2574-2582

3. Parkner T, Sørensen LP, Nielsen AR et al (2012) Soluble CD163: a biomarker linking macrophages and insulin resistance. Diabetologia 55:1856-1862

4. Ridaura VK, Faith JJ, Rey FE et al (2013) Gut microbiota from twins discordant for obesity modulate metabolism in mice. Science 341 : 1241214

5. Wu JD, Xu XH, Zhu J et al (2011) Effect of exenatide on inflammatory and oxidative stress markers in patients with type 2 diabetes mellitus. Diabetes Technol Ther 13:143-148

6. Hattori Y, Jojima T, Tomizawa A et al (2010) A glucagon-like peptide-1 (GLP-1) analogue, liraglutide, upregulates nitric oxide production and exerts anti-inflammatory action in endothelial cells. Diabetologia 53:2256-2263

7. Lee YS, Park MS, Choung JS et al (2012) Glucagon-like peptide-1 inhibits adipose tissue macrophage infiltration and inflammation in an obese mouse model of diabetes. Diabetologia 55:2456-2468

8. Chaudhuri A, Ghanim H, Vora M et al (2012) Exenatide exerts a potent antiinflammatory effect. J Clin Endocrinol Metab 97:198-207

9. Hogan AE, Tobin AM, Ahern T et al (2011) Glucagon-like peptide-1 (GLP-1) and the regulation of human invariant natural killer T cells: lessons from obesity, diabetes and psoriasis. Diabetologia 54:27452754

10. Lynch L, Nowak M, Varghese B et al (2012) Adipose tissue invariant NKT cells protect against diet-induced obesity and metabolic disorder through regulatory cytokine production. Immunity 37:574-587

11. Feingold KR, Soued M, Adi S et al (1991) Effect of interleukin-1 on lipid metabolism in the rat. Similarities to and differences from tumor necrosis factor. Arterioscler Thromb 11:495-500

12. Wisse BE (2004) The inflammatory syndrome: the role of adipose tissue cytokines in metabolic disorders linked to obesity. J Am Soc Nephrol 15:2792-2800 